\title{
Analysis of the Thermomechanical Response of Structural Cables Subject to Fire
}

\author{
Panagiotis Kotsovinos (D), Ove Arup \& Partners, London, UK \\ Athina Atalioti, Neil McSwiney, and Francesca Lugaresi, Department of Civil \\ and Environmental Engineering, Imperial College London, London, UK \\ Guillermo Rein (D), Department of Mechanical Engineering, Imperial College \\ London, London, UK
}

Adam J. Sadowski* (D), Department of Civil and Environmental Engineering, Imperial College London, London, $U K$

Received: 5 October 2018/Accepted: 5 July 2019

\begin{abstract}
Cable-supported structures such as bridges and stadia are critical for the surrounding community and the consequences arising from a major fire event can be substantial. Previous computational studies into the thermal response of cables often employed simplistic heat transfer models that assumed lump capacitance or cross-sectional homogeneity without proof of validity. This paper proposes a methodology for calculating the thermal response of a cable cross-section allowing for heat transfer by conduction through each strand contact surface and radiation across inter-strand cavities. The methodology has been validated against two experiments of cables subjected to radiant heating and an input sensitivity analysis has been undertaken for the heat transfer and material parameters. The approach is compared against simple heat transfer lumped methods for a parallel-strand cable where it is shown that these lumped models are not always conservative. The model is then coupled with a twodimensional generalised plain strain model to study the likely effect of the cross-sectional temperature gradients on the mechanical response. The study considers three qualitatively different hydrocarbon jet fire scenarios, both with and without external insulation for fire protection. It is shown that the proposed methodology can reproduce realistic cross-sectional temperature distributions with up to $50 \%$ temperature difference at the cable external surface and can capture the phenomenon of load shedding in a gradually heated cable. It is also shown that assuming a lumped thermal mass neglects the possibility of moment-inducing temperature gradients which are not considered in the ambient design of cables that is driven by tensile capacities. The proposed model and its predictions contribute towards an improved understanding and a more informed structural design of cable-supported structures in fire.
\end{abstract}

Keywords: Structural cables, Heat transfer, Cavity radiation, Conduction, Thermomechanical analysis

* Correspondence should be addressed to: Adam J. Sadowski, E-mail: a.sadowski@imperial.ac.uk 


\section{Introduction}

The design of bridges involves the assessment and evaluation of effects caused by all actions that may occur during the bridge's life. Examples include permanent, variable, wind and snow loads, as well as accidental actions such as earthquake, blast or fire. The probability of occurrence of an accidental fire event on or around a bridge leading to a structurally significant thermal load can be relatively low, but the consequences are potentially severe and may need to be strategically considered in design. The consequences depend on the associated life safety risks and the importance given to fire safety objectives such as property protection and business continuity. As the evacuation of a long span bridge may last several hours and reaching the location of the fire may be difficult by the fire services, structural resilience in a fire event is critical. Unfortunately, fire resistance requirements for bridges are not explicitly covered by national building regulations, health and safety legislation or, even, by specific owner or operator requirements. As a result, to establish appropriate fire protection measures, engineers must often resort to establishing case-specific design fires from first principles and subsequently determining the thermal and mechanical response of the structure. However, the literature on how to undertake such assessments, in particular for cable supported structures, is scarce and more research is needed.

Steel members are known to experience a degradation of their mechanical properties and expansion with temperature which can cause structural damage. An open-air fire on a cable-supported bridge deck could lead to local failure or even progressive collapse depending on the number of cables affected and their importance to load redistribution. Garlock et al. [1] and Peris-Sayol et al. [2] reported on 154 fire incidents involving partial or global collapse of road bridges with significant financial and social impact. Such fire incidents include the Charilaos Trikoupis (Rio-Antirrio) Bridge in Greece in 2005 or the Mezcala Bridge in Mexico in 2007. Both fires led to the failure of a single cable stay with damage to adjacent ones, but fortunately not to total collapse. Structural design of cables is frequently carried out only under ambient temperature conditions with only a limited degree of redundancy, often allowing for the loss of only a single cable [3]. As a result, where a number of cables may lose part of their load-bearing capacity in the event of a fire, beyond what was accounted for during design for ambient conditions, progressive collapse of the entire bridge could take place. Therefore, the accurate prediction of the fire performance of individual cable stays is an important step in the structural fire safety design of such structures.

In a cable-supported bridge, the cables are arguably the structural members most susceptible to the detrimental effects of a fire around the bridge deck due to their slender form and the potential for direct exposure to heat. Designers of cable-supported bridges thus need to conceive of a range of credible design fires on, below or around the deck, depending on the characteristics of the project, the surrounding site and existing as well as future uses for the structure. The range and the duration of these design fires must be agreed with the various stakeholders of a project $[4,5]$. Irrespectively of the selected design fire, three qualitatively 


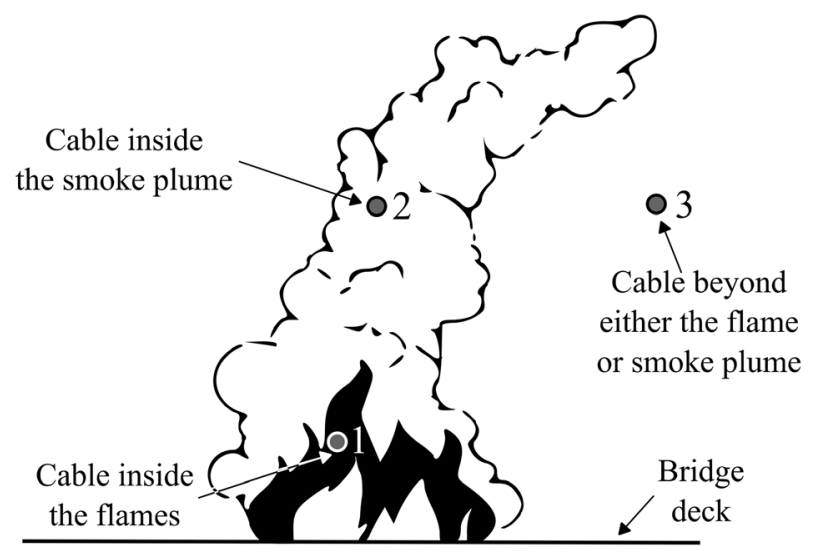

\section{Figure 1. Three possible scenarios for the cable position relative to a fire on or near the deck of a cable-supported bridge.}

different heating scenarios can generally be identified (Fig. 1): the cable being fully surrounded by flames (subject to uniform and intense heating all around), the cable being within the smoke plume (subject to non-uniform and less intense heating) and the cable being at a distance away from the fire and plume (subject to the least intense but most non-uniform heating). A single cable can experience each of these three heating scenarios throughout its length. More details about the boundary conditions for each of these three distinctively different scenarios is provided in Sect. 4 of this paper.

\section{Knowledge Gap and Scope of this Paper}

The majority of computational studies on the thermal and mechanical responses of bridge structures in fire relate to steel girder bridges. This emphasis of much of this research is a consequence of concerns raised following the MacArthur Maze bridge collapse in Oakland in 2007 and other similar fire-induced structural failures of bridges predominantly in the USA [6-8]. Experimental studies on structural cables are rare, with the most comprehensive study possibly being that of Fontanari et al. [9]. The majority of studies have been computational in nature [10-13] and have considered bridge cable stays exposed to hydrocarbon fires using simplified heat transfer models. The difficulty is compounded by the fact that many different forms of structural cables exist; parallel strand, spiral strand, wire rope strand and locked coil strand, though all types have in common that they consist of a varying number of strands depending on the cable diameter and cavities in between the strands. Each strand in turn is usually a tight bundle of a varying number of high-strength wires. A typical layout of a parallel-strand cable with a hexagonal arrangement is shown in Fig. 2.

Four different approaches to analysing the thermal response have been identified in the literature, summarised as follows in order of increasing complexity. In 
a

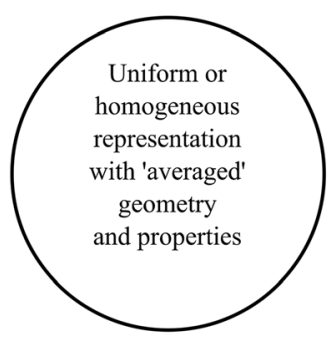

b

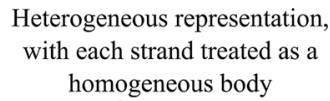

Heterogeneous representation,

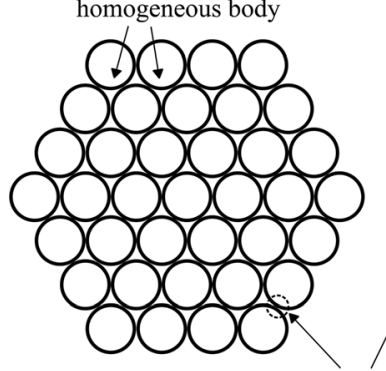

Conduction and radiation c Protective homogeneous sleeve

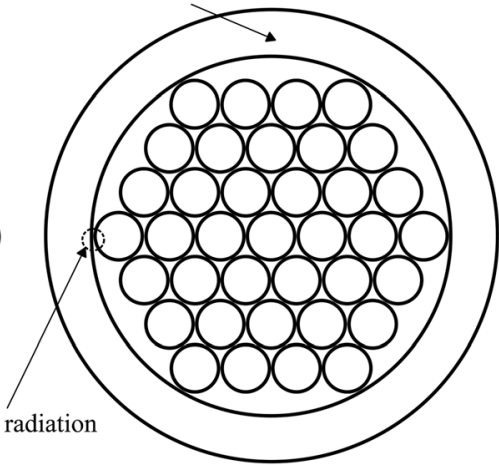

\section{Figure 2. Heat transfer model representations for typical parallel- strand hexagonal arrangements: (a) uniform, (b) unprotected heterogeneous and (c) protected heterogeneous.}

the first, Quiel et al. [12] conducted a 1D heat transfer analysis of a parallel-strand cable, determining the cable temperature using a lumped thermal mass approach neglecting thermal gradients. In the second, Bennetts and Moinuddin [10] adopted a $2 \mathrm{D}$ heat transfer approach treating each ring of strands as an individual lumped thermal mass, with the heat transfer between the rings of strands occurring solely by radiation. In the third, Main and Luecke [11] carried out a 3D conduction heat transfer analysis of a parallel-wire cable assuming a uniform cross-section without internal cavities for the whole cable. Finally, Fontanari et al. [9] considered a detailed 3D model of a wire rope strand which included conduction and mechanical contact between the strands, but not radiation. While the study of Fontanari et al. [9] is perhaps the most advanced treatment undertaken to date in the literature, in their chosen thermal response parameters of the cable in the study (namely the global heat transfer coefficient between air and exterior of the cable) the contact heat resistances between the wires and between the strands were calibrated directly against experimental results without prediction by algebraic formulae. Specifically, the calibration was conducted until the temperatures-time relationships at different positions of the cross section were reproduced and a comprehensive heat transfer model was therefore not considered. However, Fontanari et al. [9] is the only study in the literature that has considered the mechanical response of cables and established the failure strain based on the cable type (wire rope and locked coil types were considered) and diameter.

Each of the aforementioned studies effectively considered only the fire scenario of direct flame exposure (scenario 1 in Fig. 1) leading to uniform cross-sectional heating, typically under a prescribed temperature-time curve. The thermal exposure of a cable within the plume or away from the fire (scenarios 2 and 3 respectively), where heating is non-uniform, does not appear to have been considered. The aim of this paper is to offer a rigorous two-dimensional heat transfer methodology (adopted in ABAQUS) for use in the analysis of any cable cross-section, 
considering heat transfer between the strands by both radiation and conduction across inner cavities and contact surfaces. The method is validated against two experiments of cables subjected to radiant heating and an input sensitivity analysis has been undertaken for the heat transfer and material parameters. The appropriateness of adopting simplified models, such as those described in previous literature which rely on various assumptions of temperature uniformity, is compared with the proposed method. The possible structural consequences of a uniform or heterogeneous strand model under the three heating scenarios are explored via a thermomechanical coupling under generalised two-dimensional plane strain conditions. The methodology is presented in the form of a general thermomechanical model that contains the relevant physics, with the understanding that further comparisons with experimental evidence will be carried out in future research as it becomes available.

\section{Thermomechanical Response of a Heterogeneous Cable}

\subsection{Thermal Response}

Both uniform (or homogeneous) (Fig. 2a) and heterogeneous (Fig. 2b) cable heat transfer models are compared in this paper. The failure of cable stays is often assessed on the basis of a 'critical' temperature of $300^{\circ} \mathrm{C}$ [3], yet a significant amount of air cavities exists between the strands and ignoring these in a uniform cross-section treatment may underestimate the thermal resistance that they offer to heat flow. This potentially underestimates the non-uniformity of the cross-sectional temperature distribution as well as the associated thermal gradients, differential thermal expansion of the strands and potential thermally-induced bending moments. A representative hexagonal parallel-strand arrangement is considered here (Figs. 2b, 3), although the proposed methodology is equally applicable to other cable geometries (e.g. spiral strand and locked coil cables with prismatic and helically-wound 3D arrangements).

The geometry of a parallel-strand cable was assumed due to its simple form and also because it is the form most commonly employed in the design of long span cable supported bridges. Each strand was treated as a circular body, representing either a complete wire [14] or a tightly-packed bundle of galvanized wires ignoring interstitial air cavities [15]. In practice, each strand is sometimes sheathed in a thin High-Density Polyethylene (HDPE) sleeve (Fig. 2c) for the purposes of corrosion resistance, where HDPE is a polymer that degrades completely at temperatures between $200^{\circ} \mathrm{C}$ and $400^{\circ} \mathrm{C}$ [16]. The influence of such an HDPE sleeve on interstrand heat transfer was omitted from the current analysis as such a sleeve is not always present and its thermal resistance would likely disappear very early during the heating process. An accurate assessment of the modes of heat transfer between the cable strands requires a characterisation of the thermal resistances resulting from the contacting strand surfaces $R_{s}$ and interstitial air cavities $R_{i}$ (Fig. 3), and is presented as follows. Note that depending on the type and arrangement of sleeves around the strands, its degradation at elevated temperatures could also have an 


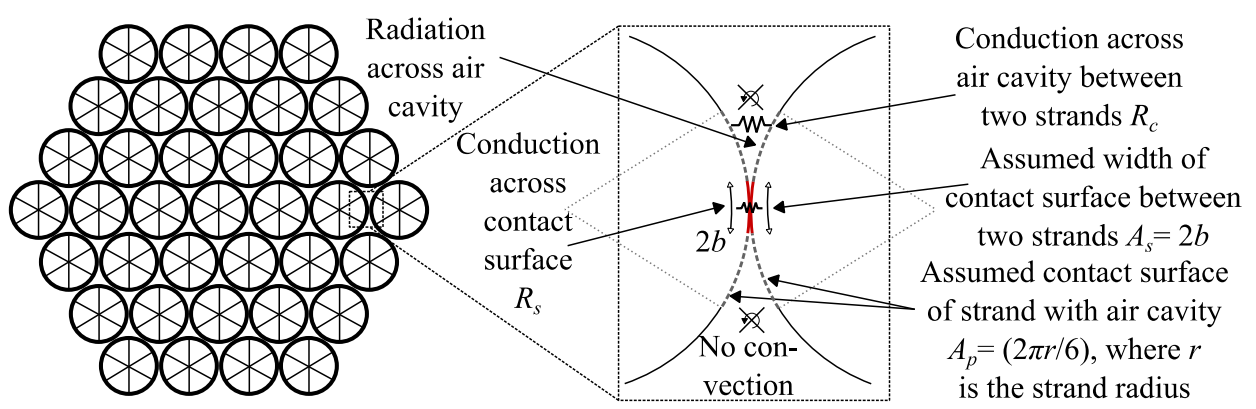

Figure 3. Components of heat transfer between the cable strands
(assumed per unit length).

impact on the contact between the strands. The effect of such degradation on the contact conditions between the strands requires further experimental research if it is to be defined in a numerical model, and it was not considered here.

\subsubsection{Conductive Heat Transfer Across the Contact Surface of Strands Heat trans-} fer by conduction occurs between two strands in contact, where the arc length of the contact depends on the force between the strands and its modulus of elasticity. The half-width $b$ (see Fig. 2b) of the contact of two cylindrical solid bodies of equal diameter and material (i.e. the strands) may be expressed as $[17,18]$ :

$$
b=\sqrt{\frac{8 F D\left(1-v^{2}\right)}{E L \pi}}
$$

where $F$ is the normal contact force between the strands, $v$ is the Poisson ratio, $D$ is the diameter of the strand and $L$ is the strand length (taken as a unit value for $2 \mathrm{D}$ cross-sectional analysis). The contact resistance for a strip of contact width of $2 b$ is given by [18]:

$$
R_{c}=\frac{1}{L k}\left[\frac{1}{\pi} \ln \left(\frac{2 D}{b}\right)-\frac{1}{2}\right]
$$

where $L, D$ and $k$ are the length, dimeter and thermal conductivity of the strands. The total contact resistance, accounting for strips on both strands, is thus given by:

$$
R_{s}=2 R_{c}
$$

A wire is usually wrapped around the circumference of the cable to keep the system together, and the resulting clamping action introduces normal contact forces between strands. This contact force will be dependent on the cable characteristics and a sensitivity study was carried out to evaluate the effect of the contact force, taken as a multiple of the strand self-weight, on the contact resistance. It was pro- 
visionally determined that the resistance is largely insensitive to the magnitude of the contact force, which was then adopted as equal to the self-weight of the strand for illustration purposes in this paper. Future research should explore this parameter further.

3.1.2. Heat Transfer Across Interstitial Air Cavities Heat transfer across a cavity occurs via convection if the air is in motion, via conduction if it is stationary and, in both cases, additionally via radiation. For natural convection to occur, the buoyancy forces in the air cavity must overcome the resistance imposed by viscous forces to cause air motion, unlikely in cavities that are too small. This phenomenon can be assessed using the Rayleigh number $R a$ (Eq. 4; [19]) which strongly depends on the cavity thickness $\delta$. When $R a$ does not exceed 1708, buoyancy forces cannot overcome viscous forces and thus natural convection cannot occur.

$$
R a=\frac{g \beta\left(T_{1}-T_{2}\right) \delta^{3}}{\alpha v}<1708
$$

In the case of small cavities, the thermal resistance due to conduction across the interstitial air cavity depends on its thickness and the thermal diffusivity of air $(\alpha)$. The strand surface that is in contact with air $A_{p}$ is taken as one-sixth of the strand circumference and the contact surface $A_{s}$ is deduced from the half-width $b$ (Eq. 1) of any two adjacent strands. The resistance to conduction of the interstitial air cavity when $R a$ does not exceed 1708 is then given by:

$$
R_{i}=\frac{L}{k_{\text {air }}\left(A_{p}-A_{s}\right)}
$$

In addition to convection and conduction, heat transfer across the cavity occurs by radiation along the area $A_{p}$ according to the linearised radiative resistance:

$$
R_{r}=\frac{1}{h_{r} A_{p}} \quad \text { where } h_{r}=\varepsilon \sigma\left(T_{1}^{2}+T_{2}^{2}\right)\left(T_{1}+T_{2}\right)
$$

In the above, $h_{r}$ is the radiative heat transfer coefficient, $\sigma$ is the Stefan-Boltzmann constant, $\varepsilon$ is the system emissivity, while $T_{1}$ and $T_{2}$ are the temperatures of two adjacent strand surfaces.

3.1.3. Total Thermal Resistance Between Strands The total thermal resistance between two adjacent strands is obtained by combining the interstitial air cavity resistance, the contact surface resistance and the radiative resistance, assuming a parallel arrangement:

$$
\frac{1}{R_{t}}=\frac{1}{R_{i}}+\frac{1}{R_{s}}+\frac{1}{R_{r}} \Rightarrow R_{t}=\frac{R_{i} R_{s} R_{r}}{R_{i} R_{r}+R_{i} R_{s}+R_{r} R_{s}}
$$




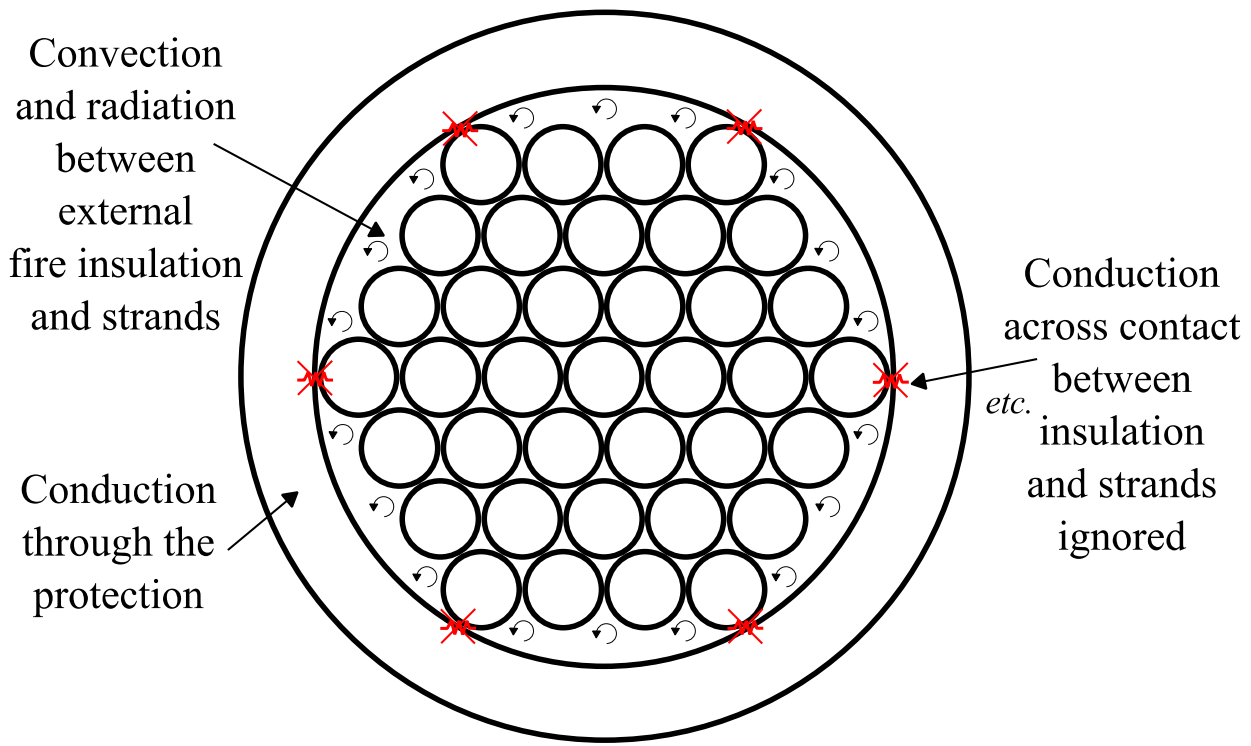

Figure 4. Components of heat transfer bełween external fire insulation and the strands.

3.1.4. Heat Transfer Between the External Insulation and the Strands Insulation material is often applied to the exterior of cables to limit the heating experienced by the load-carrying strands and thus delay mechanical failure. Heat transfer between the insulation and the strands occurs mostly by natural convection and radiation (see Fig. 4), as the cavity in this case is sufficiently large to generate convective flows. The conductive heat transfer through the insulation is considered in the model as well as the convection and radiation between the external insulation and the strands. Heat transfer by conduction across the contact between the insulation and strands is ignored as the insulation is a poor conductor and the contact surfaces are small. The thermal resistance is therefore:

$$
R_{t}=\frac{1}{h}
$$

where $h$ is the convective heat transfer coefficient of the insulation surface.

\subsection{Plane Strain Mechanical Response}

The preceding thermal model of the heterogeneous cable arrangement was implemented in the ABAQUS [20] commercial finite element software. To investigate the subsequent structural behaviour of the heated unprotected cable cross-section under the three fire scenarios (Fig. 1), the model was enhanced to permit a generalised plane strain thermomechanical response. In ABAQUS, a generalised plane 
strain model represents a cross-section through an 'infinitely long' member, an assumption commensurate with the characteristics of a parallel-strand cable stay as examined in this paper, that is able to adopt a constant curvature in two orthogonal directions. The $2 \mathrm{D}$ cross-section was assumed to be bounded by two planes a unit thickness apart, whose freedom to displace is linked to the degrees of freedom (dofs) of a reference point at the cross-section centroid (Fig. 5a). A condition of zero biaxial curvature (cross-section bounded by parallel planes, representing a prismatic cable) was enforced by restraining the rotational dofs of this reference point (i.e. those about the $x$ and $y$ axes). If the cable cross-section is heated non-uniformly and temperature gradients appear, the restraint offered by the parallel bounding planes to the curvatures would instead cause bending moments to develop about the section centroid [21]. A tensile force representing a realistic level of constant pre-loading was additionally applied to the cable before the transient heat transfer analysis, and the cross-section centroid was at all times free to displace along the longitudinal $z$ axis. To prevent spurious in-plane rotation of the strands during heating, the dofs at the outer perimeter of every strand were restrained to prevent circumferential displacement, though radial expansion was still permitted (Fig. 5b). Additionally, to prevent rigid body motion of the expanding strands in the $x-y$ plane during heating, the centroid of each strand was joined to the centroids of each neighbouring strands by a $1 \mathrm{D}$ axial spring (assumed for the purposes of illustration to have a stiffness of $10^{8} \mathrm{~N} \mathrm{~mm}$, representing a bundle of strands held together quite firmly).

It should be clarified that a $2 \mathrm{D}$ representation was adopted by the authors with the primary intent to capture the effects of unsymmetrical heating in the cross-section and load redistribution between the strands under idealised conditions. Future research will focus on developing appropriate 3D models that can capture effects such as the influence of terminal connections, thermal creep, stress relaxation and the differential thermal expansion of the strands, amongst others. Such models would likely require significant input from experimental data of loaded cables subjected to both uniform and non-uniform heating.

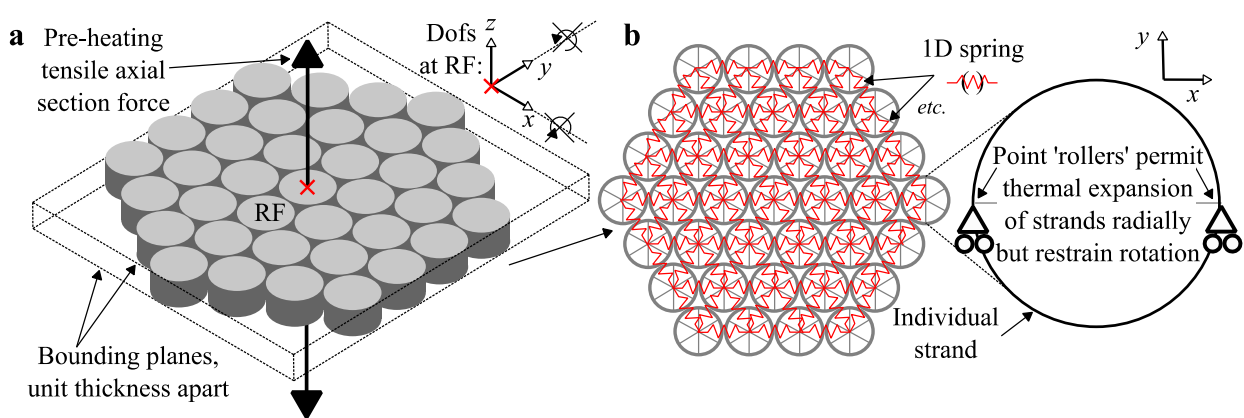

\section{Figure 5. Mechanical boundary conditions for a plane strain cross- sectional model.}




\subsection{Thermal and Mechanical Material Properties}

The thermal and mechanical models presented previously are independent of the properties of the constituent materials and may be used with any temperature dependency. However, for the purposes of illustration, the process of establishing appropriate input properties for high-strength steel is described here. Values for the thermal conductivity $(45.5 \mathrm{~W} /(\mathrm{mK})$ at ambient $)$ and specific heat $(450 \mathrm{~J} /(\mathrm{kgK})$ at ambient) of high-strength pre-stressed steel wire were adopted from Main and Luecke [11], where these are given as a function of temperature up to $\sim 726^{\circ} \mathrm{C}$ $(\sim 1000 \mathrm{~K})$ at which point recrystallisation of the steel takes place. Given that a fire potentially exposes a cable to temperatures significantly in excess of this limiting temperature, it is necessary to extend the characterisation above the phasechange temperature. However, because the conductivity and specific heat for highstrength steel from Main and Luecke [11] follow those for mild carbon steel from EN 1993-1-2 [22] rather closely, and since the latter has a significantly higher upper limit of $1200^{\circ} \mathrm{C}(1473 \mathrm{~K})$, it was decided to adopt the EN 1993-1-2 properties for mild steel beyond $726^{\circ} \mathrm{C}$. The density of steel $\left(7850 \mathrm{~kg} / \mathrm{m}^{3}\right)$ was assumed to be independent of temperature.

The mechanical properties of high-strength steel wires under elevated temperatures, including the initial modulus of elasticity $E$ (200 GPa at ambient), the yield stress (1422 MPa at ambient), ultimate stress (1784 MPa at ambient), Poisson ratio $v\left(0.29\right.$ at ambient) and the coefficient of thermal expansion $\left(1.07 \times 10^{-5} \mathrm{~K}^{-}\right.$ ${ }^{1}$ at ambient), were similarly constructed using the data sourced by Main and Luecke [11] up to $\sim 726^{\circ} \mathrm{C}$, with the relationship beyond this temperature corrected by data from EN 1993-1-2 [22] for mild steels. These properties were used in conjunction with a simple bilinear stress-strain law at all temperatures. It should be noted that high-strength steel loses most of its strength benefits beyond this phase change, a region where accurate thermal and mechanical properties are in any case difficult to establish reliably. Nonetheless, further research is recommended to establish more accurate relationships for high-strength steels in critical structural applications, currently not available.

The properties of the fluid in the interstitial cavities were assumed to be those of dry air [19], whose density decreases significantly with temperature. The thermal properties of the external insulation were taken from a typical commercial fire protection blanket (F120, Class A2) with a fire resistance of $60 \mathrm{~min}$ [23]. The thermal conductivity, specific heat and density were taken as $0.2 \mathrm{~W} /(\mathrm{mK}), 1009 \mathrm{~J} /$ $(\mathrm{kgK})$ and $100 \mathrm{~kg} / \mathrm{m}^{3}$ respectively, independent of temperature due to lack of such further data by the manufacturer. The blanket was assumed to contribute negligibly to the stiffness of the cable, and was assigned a nominal elastic modulus of $1 \mathrm{~N} / \mathrm{m}^{2}$ and a Poisson ratio of zero. Where a uniform cable cross-section was studied for comparison purposes (Fig. 1a), the thermal and mechanical material properties were obtained as an area-weighted average of the properties of the individual constituent materials, namely steel and air (on the basis that interstitial air comprises $6.97 \%$ of the cross-section studied here, the dimensions of which are presented shortly): 


$$
x_{u}=\frac{x_{s} A_{s}+x_{a} A_{a}}{A_{s}+A_{a}}
$$

where $x$ is any relevant temperature-dependent thermal property, while the subscripts ' $u$ ', 's' and ' $a$ ' denote 'uniform', 'steel' and 'air' respectively.

\subsection{Validation of the Thermal Response and Input Sensitivity}

The Appendix describes a validation study of the heat transfer methodology presented in Sect. 3.1 against the two cable experiments subjected to radiant heating recently conducted by Lugaresi [27], together with a sensitivity study of model to the key heat transfer and material parameters. The validation study has shown that the proposed heat transfer methodology compares well against the experimental results producing the trends of the thermal gradients within the cables. For the sensitivity study, five heat transfer parameters were considered: heat flux, contact force, contact width, temperature of the fluid, and convective coefficient. Six steel material parameters were also considered: conductivity, emissivity, density, specific heat, Poisson ratio and elastic modulus. It was shown that of all the input parameters to the heat transfer model, the variation of the surface heat flux $q$ " produced the largest variation in the model output, while the thermal conductivity of the steel was found to be the governing material parameter. Further details and results may be found in the Appendix.

\section{Design Fire Scenarios}

The design fire considered in this study is that of a hydrocarbon jet fire with a flame height of $40 \mathrm{~m}$ caused by a $10 \mathrm{~kg} / \mathrm{s}$ petrol leakage through a cavity of a diameter of $30 \mathrm{~mm}$, realistic for a jet fire caused by a heavy goods vehicle. Such fires are known to be of long duration and high heat release rate, and thus likely to be structurally significant. A steady-state fire was considered to burn at max heat release rate for up to $120 \mathrm{~min}$, thought sufficiently long to capture any potential failure mechanisms under the assumption that the fire has not been suppressed. The simulations were continued beyond the 'onset of irreversible damage' temperature of $300^{\circ} \mathrm{C}(573 \mathrm{~K})$, the recommended temperature failure criterion in the fire testing classification of prestressing stay cables [3]. Data on jet fires are taken from Lowesmith et al. [24].

A total of nine thermomechanical simulations were carried out as part of this study, each simulation corresponding to a combination of a cable cross-section configuration and a fire scenario. The cable configurations included a 'uniform' (or homogeneous) cross-section, an 'unprotected heterogeneous' cross-section consisting of a hexagonal arrangement of 37 uniform circular strands including interstitial air cavities, and a 'protected heterogeneous' cross-section consisting of the latter strand arrangement including a 15-mm circular exterior insulation (Fig. 2). The actual dimensions of each configuration are summarised in Table 1. Prior to the application of any thermal load, the heterogeneous configurations were subject to an axial pre-load applied through the centroidal reference point (Fig. 4). The 


\section{Table 1}

Dimensions of Each Cable Configuration

\begin{tabular}{lccc}
\hline & Uniform & $\begin{array}{c}\text { Unprotected } \\
\text { heterogeneous }\end{array}$ & $\begin{array}{c}\text { Protected } \\
\text { heterogeneous }\end{array}$ \\
\hline Net section diameter $(\mathrm{mm})$ & 99.00 & 111.00 & 141.00 \\
Strand diameter $(\mathrm{mm})$ & $\mathrm{n} / \mathrm{a}$ & 15.71 & 15.71 \\
Horizontal spacing $^{\dagger}(\mathrm{mm})$ & $\mathrm{n} / \mathrm{a}$ & 15.71 & 15.71 \\
Vertical spacing $^{\dagger}(\mathrm{mm})$ & $\mathrm{n} / \mathrm{a}$ & 13.65 & 13.65 \\
Protection thickness $(\mathrm{mm})$ & $\mathrm{n} / \mathrm{a}$ & $\mathrm{n} / \mathrm{a}$ & 15.00 \\
Spacing between insulation and strands $(\mathrm{mm})$ & $\mathrm{n} / \mathrm{a}$ & $\mathrm{n} / \mathrm{a}$ & 0.52 \\
\hline
\end{tabular}

${ }^{\dagger}$ Evaluated between strand centres, based on the orientation shown in Fig. 2

magnitude of this load was taken as $N=f_{u} A_{s} n_{s} / \gamma \approx 6.4 \mathrm{MN}$, assuming an ultimate strength of $1784 \mathrm{MPa}, n_{s}=37$ strands with cross-sectional area $A_{s}$ corresponding to a diameter of $15.7 \mathrm{~mm}$ and a safety factor of $\gamma=2$ [11].

For flame heights up to $40 \mathrm{~m}$ [24], a cable may find itself either fully inside the flames (scenario 1), outside the flames but fully within the smoke plume (scenario 2), or in proximity to both but in direct contact with neither (scenario 3 ). These scenarios were illustrated in Fig. 1. In the first exposure scenario, a cable fully surrounded by flames is assumed to be heated by convection and radiation along its full outer perimeter, although heat is also emitted back to the ambient environment (Fig. 6a). The cross-section is thus heated uniformly from all sides. In the second exposure scenario, a cable is within the smoke plume and heated only by convection around its full perimeter from the buoyant hot smoke gases. It is assumed that radiation from the flames impinges only on a half-perimeter of the cable, although the cable still reradiates heat to the ambient environment along its entire perimeter (Fig. 6b). The cross-section will thus exhibit a uniaxial temperature gradient. In the third exposure scenario, a cable located at a distance away from both the flames and the smoke plume is assumed to be heated only by radiation along a quarter of its perimeter, although the entire heated cross-section radiates back to the ambient environment $(293 \mathrm{~K})$ and cools through convection (Fig. 6c). In this case, the cross-section will exhibit a biaxial temperature gradient.

The incident radiative flux received by the cable from the surrounding flames in scenario 1 was taken as $180 \mathrm{~kW} / \mathrm{m}^{2}$ [24]. In fire scenarios 2 and 3, the incident flux was taken as $23 \mathrm{~kW} / \mathrm{m}^{2}$ assuming that the cable cross-section is situated $15 \mathrm{~m}$ away from the flames and using the point source simplified calculation method [24]. In all scenarios, the incident radiation was treated as a constant surface heat flux on the outer perimeter of the cross-section. The emissivity of the uniform and unprotected heterogeneous configurations was taken as 0.62 [10], whereas that of the protected configuration was taken as 0.9 [19]. For the purposes of establishing the convective heat flux, it was assumed that the temperature of the smoke plume was $\sim 227^{\circ} \mathrm{C}$ or $500 \mathrm{~K}$ [25], a value adopted from data for hydrocarbon pool 


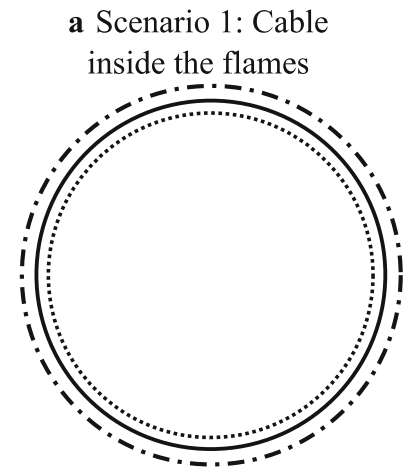

Radiation: Received Emitted b Scenario 2: Cable inside the smoke plume c Scenario 3: Cable beyond the flame or smoke plume
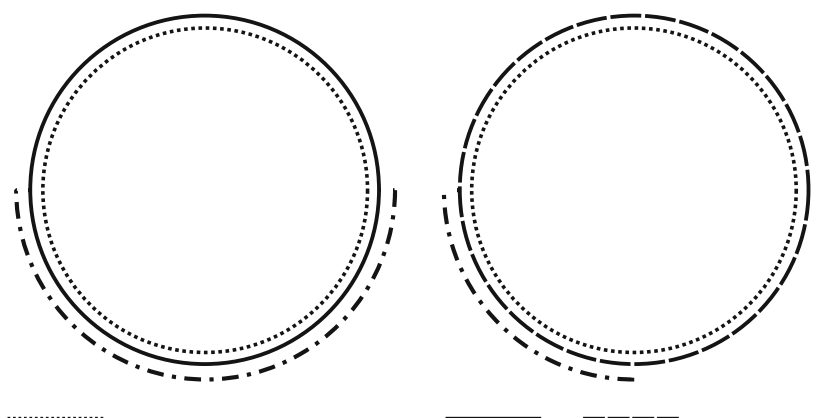

Convection: Heating Cooling

\section{Figure 6. Heat transfer components at the external surface for each fire scenario.}

fires, whereas the temperature of the flames was $\sim 1287^{\circ} \mathrm{C}$ or $1560 \mathrm{~K}$ [24]. The convective heat transfer coefficient for fire scenario 1 was taken as $95 \mathrm{~W} /\left(\mathrm{m}^{2} \mathrm{~K}\right)$ from Lowesmith et al. [24], but for scenario 2 it was estimated using the Nusselt number as $20.3 \mathrm{~W} /\left(\mathrm{m}^{2} \mathrm{~K}\right)$.

\section{Predicted Thermo-Mechanical Response}

\subsection{Fire Scenario 1}

A selection of predicted evolutions of temperatures with time is presented in Fig. 7 for the first fire scenario where the cable is subject to intense heating from all sides. The temperature development was investigated at three locations across the cross section of the three cable configurations (uniform and both unprotected and protected heterogeneous), namely at the outer perimeter (location A in Fig. 7), midpoint through the (effective) section radius (location B) and at the section centroid (location C). Although the uniform and unprotected heterogeneous models offer reasonably close predictions of the temperature evolution, the simpler uniform treatment underestimates the temperatures near the section perimeter by an approximate maximum of $10 \%$ and overestimates the temperatures closer to the section centroid by an approximate maximum of $20 \%$. However, both treatments suggest that the onset of damage temperature of $300^{\circ} \mathrm{C}$ or $573 \mathrm{~K}$ is reached after only approximately $60 \mathrm{~s}$ of axisymmetric heating, whereas in the protected section this is delayed for approximately $40 \mathrm{~min}$. Also shown in Fig. 7 is the development of the normalised temperature difference across the section as a metric of assessing the validity of a lumped capacitance assumption, based on the results from the unprotected heterogeneous configuration. This error in lumped capacitance is defined as follows and expressed as a percentage: 


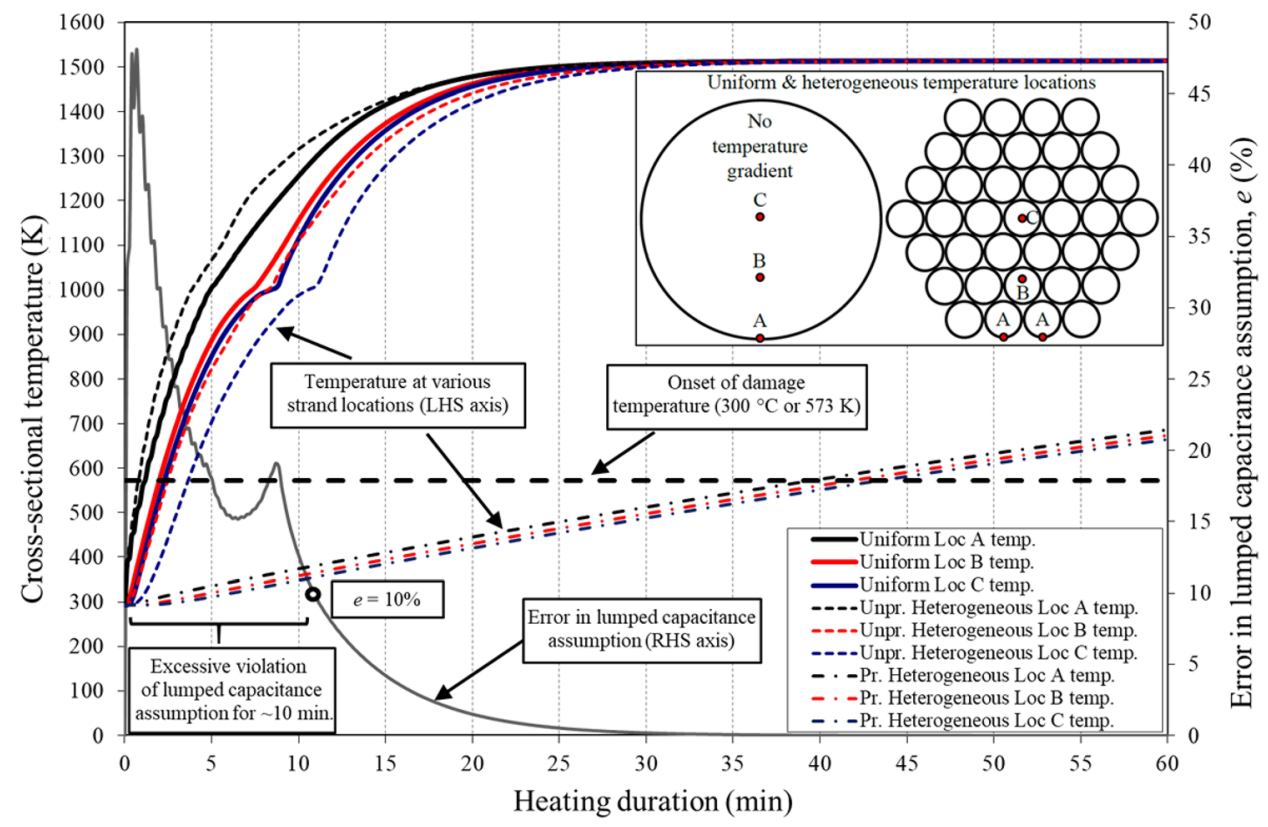

Figure 7. Temperature-time distributions at different locations in the uniform and heterogeneous configurations for fire scenario 1 and the error in lumped capacitance based on the heterogeneous configuration. "Pr." denotes the heterogeneous configuration with 120 min blanket fire protection.

$$
e=\frac{T_{\max }-T_{\min }}{T_{\min }}
$$

If valid, such an assumption would potentially permit the section to be represented as being at a uniform temperature. It is assumed that the aforementioned ratio should not exceed $10 \%$ for lumped capacitance to be valid.

It is shown here that the lumped capacitance assumption is not appropriate for the first $10 \mathrm{~min}$ of heating due to the fast heat transfer rate and delayed transient heat transfer into the bulk of the section, evident by $e$ values approaching $50 \%$. Eventually, the section temperatures reach a steady-state and a lumped capacitance assumption becomes approximately representative, however this occurs after significant temperatures have been obtained and therefore too late since predictions would be wrong in time and no longer of practical importance. Thermal gradients are important for loaded cables since they can lead to differential thermal expansion of the strands which can lead to potential uncoiling and potentially increased magnitudes of thermally-induced moments, as illustrated shortly. 


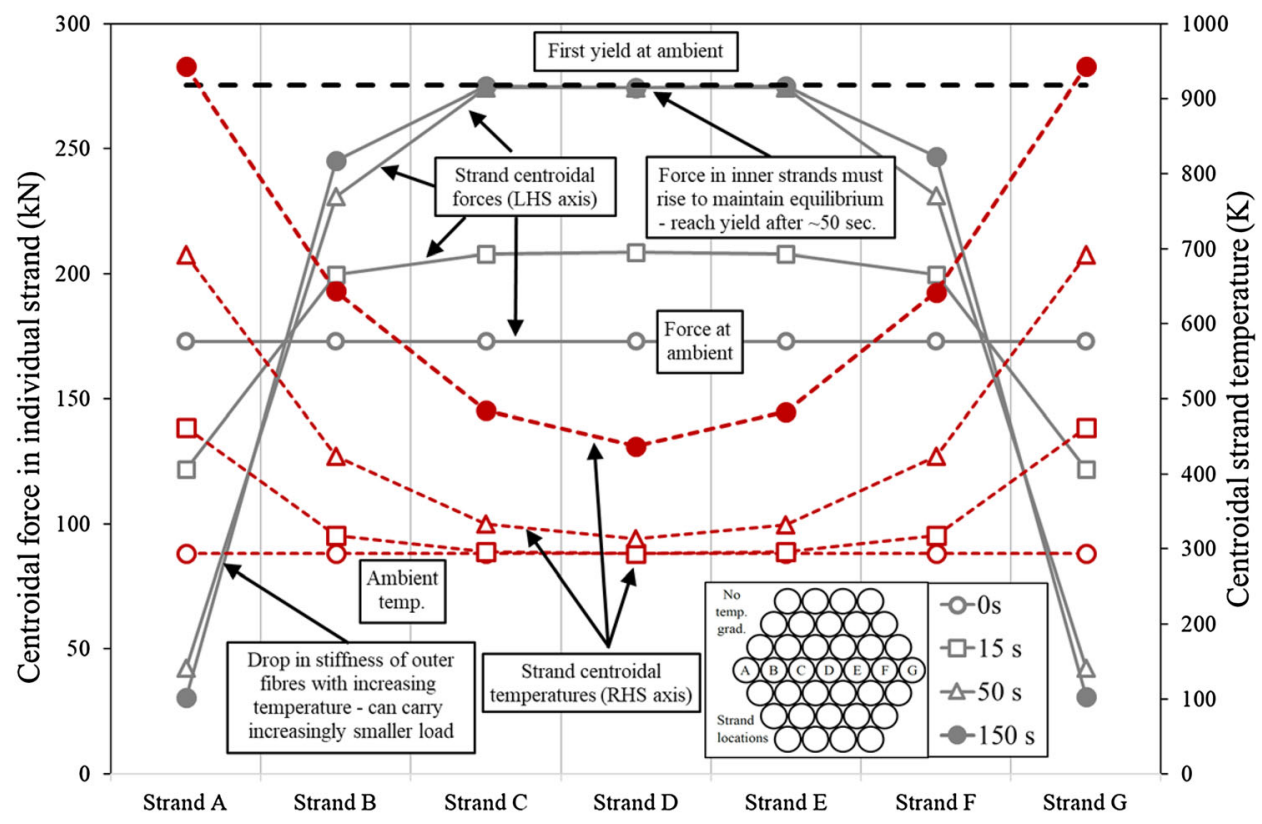

Figure 8. Centroidal axial forces and temperatures in individual strands as a function of time in the unprotected heterogeneous configurations for the fire scenario 1 .

A more complete picture of the behaviour is offered by considering the evolution of the net centroidal strand forces with time and temperature (Fig. 8). As the outer strands heat up faster, they suffer a degradation in their elastic stiffness. However, as each strand must undergo the same total axial strain, the axial load that the outer strands are able to support must also decrease correspondingly. To preserve cross-sectional equilibrium at the 6.4 MN pre-load level, the cooler innermost strands whose stiffness has not yet degraded must therefore carry a higher axial load. As a consequence, the innermost cool strands are at risk of mechanical damage even without thermal attack and indeed were found to reach yield in less than $\sim 50 \mathrm{~s}$, rather earlier than the predicted time at which the outermost strands reach the 'onset of damage' temperature. This 'load shedding' phenomenon has been reproduced computationally before [9] and illustrates the importance of performing a thermomechanical analysis to obtain an accurate assessment of the behaviour of a complex multi-strand cable cross-section under thermal loading. Lastly, it should be noted that although the heating is nominally uniform around the section, asymmetries in the heterogeneous configurations lead to very minor biaxial bending moments (Fig. 9). 


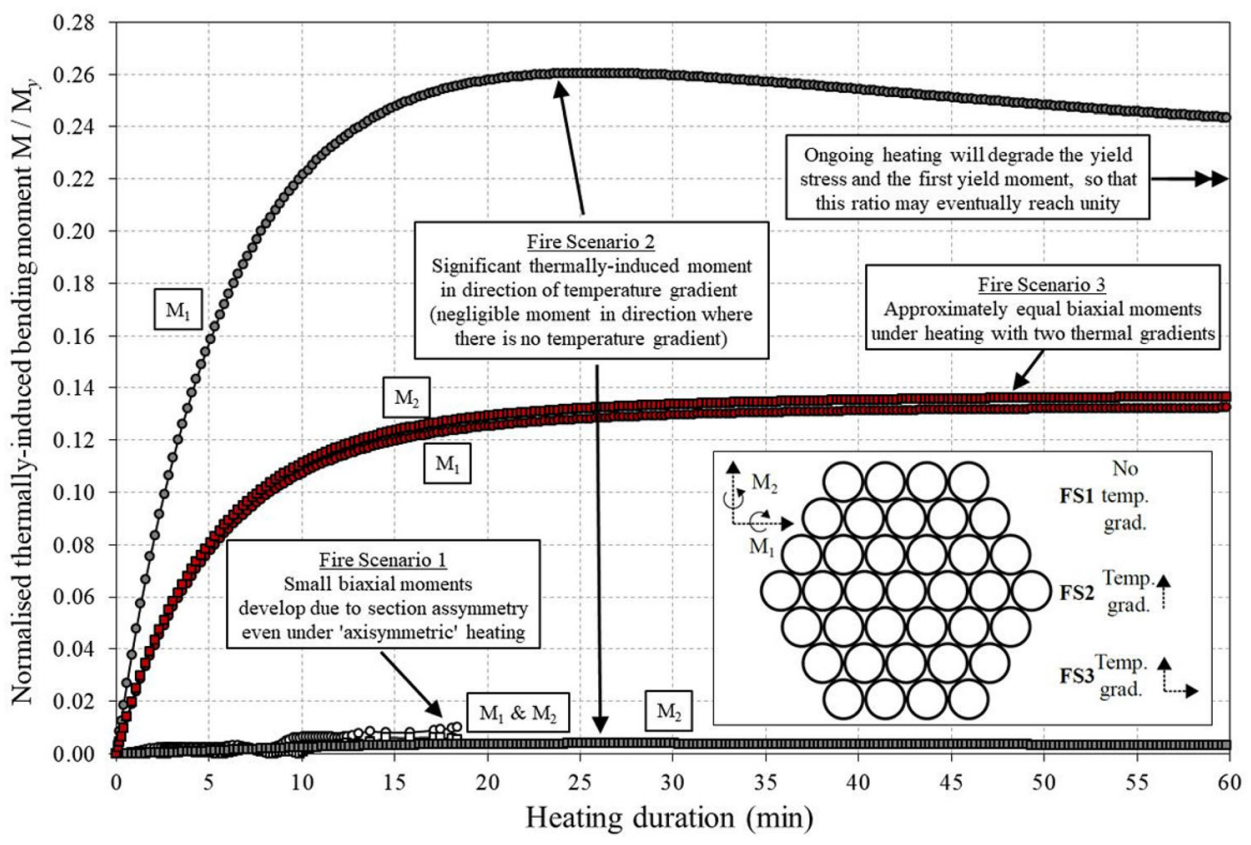

Figure 9. Variation of the cross-sectional thermally-induced bending moment as a function of the heating duration for all three fire scenarios, normalised by the first yield moment at ambient temperafure.

\subsection{Fire Scenario 2}

In the second fire scenario, the predicted evolution of temperatures at various cross-sectional locations in the direction of the uniaxial temperature gradient, namely facing the radiative flux (location A), at the centroid (location B) and opposite the heat flux (location C), is illustrated in Fig. 10. The uniform or homogeneous cable cross-section treatment now offers a very unconservative assessment of the temperature evolution in this fire scenario, suggesting that the 'onset of damage' temperature is reached after approximately $40 \mathrm{~min}$ in location A whereas the more realistic heterogeneous treatment suggests this could occur much sooner after only approximately $22 \mathrm{~min}$. The protected cable does not suffer damage within two hours of heating and predicts a more uniform cross-sectional temperature distribution.

The thermomechanical response is illustrated in Fig. 11, where a similar but more modest 'load shedding' phenomenon sees an increase in the centroidal forces of the coolest strands opposite the surface in receipt of the radiative heat flux. 


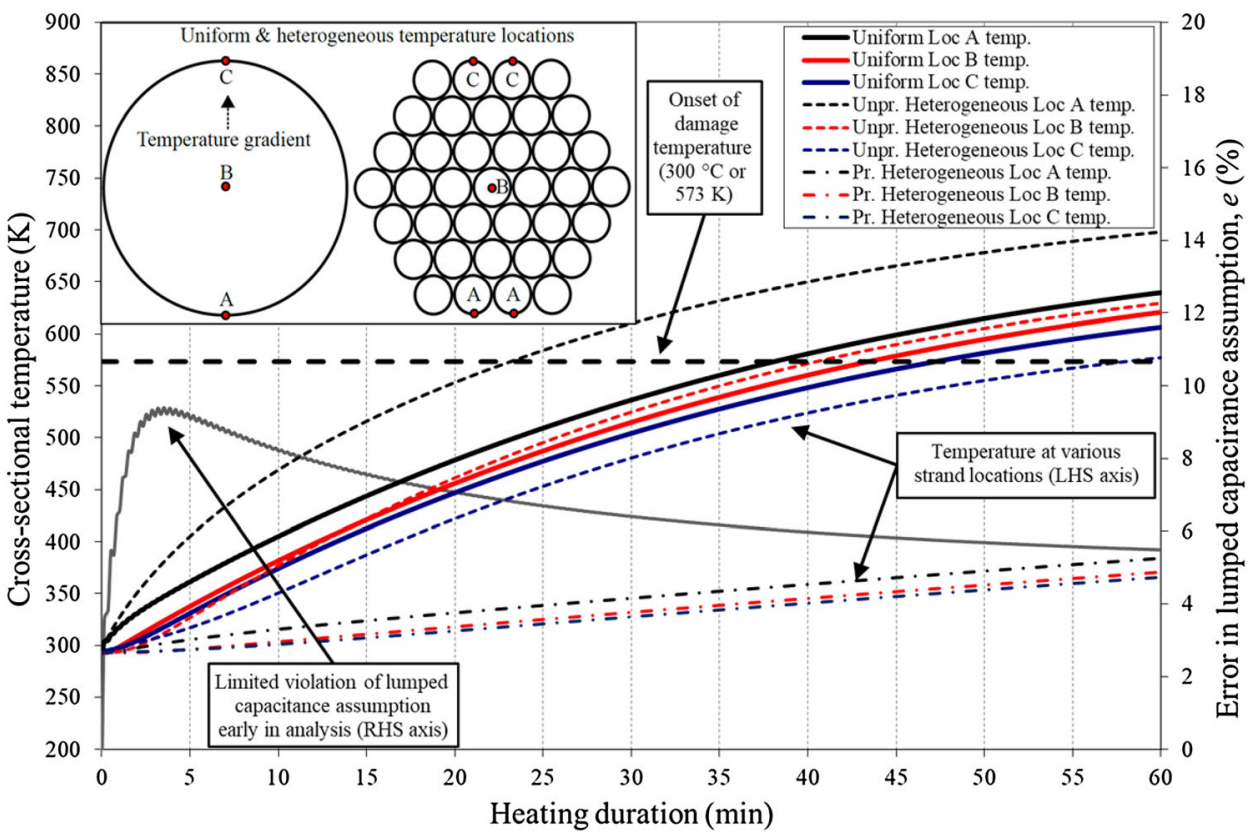

\section{Figure 10. Temperature-time distributions at different locations in the uniform and heterogeneous configurations for fire scenario 2 and the error in lumped capacitance based on the heterogeneous configuration. "Pr." denotes the heterogeneous configuration with 120 min blanket fire protection.}

This redistribution causes a net bending moment to develop in the direction of the temperature gradient (Fig. 9), where the maximum is approximately equivalent to $26 \%$ of the ambient moment that would cause first yield, clearly an undesirable response for a critical tension member that may not have been designed for bending under ambient conditions. This response would be entirely missing from a lumped capacitance treatment that is often used as the basis of simplified design, even if the error $e$ reaches a modest maximum of only $9 \%$ suggesting that lumped capacitance could be appropriate. As a result, it has been illustrated that while lumped capacitance may be 'valid' according to a simple criterion, a thermal analysis may not by itself always be conservative in giving an accurate estimate of mechanical failure. Additionally, the thermomechanical response illustrates the importance of investigating unsymmetrical heating regimes specifically as these permit the exploration of a qualitatively different structural behaviour than what is possible under uniform heating regimes where the aim of the treatment is only to maximise the equivalent uniform section temperatures. 


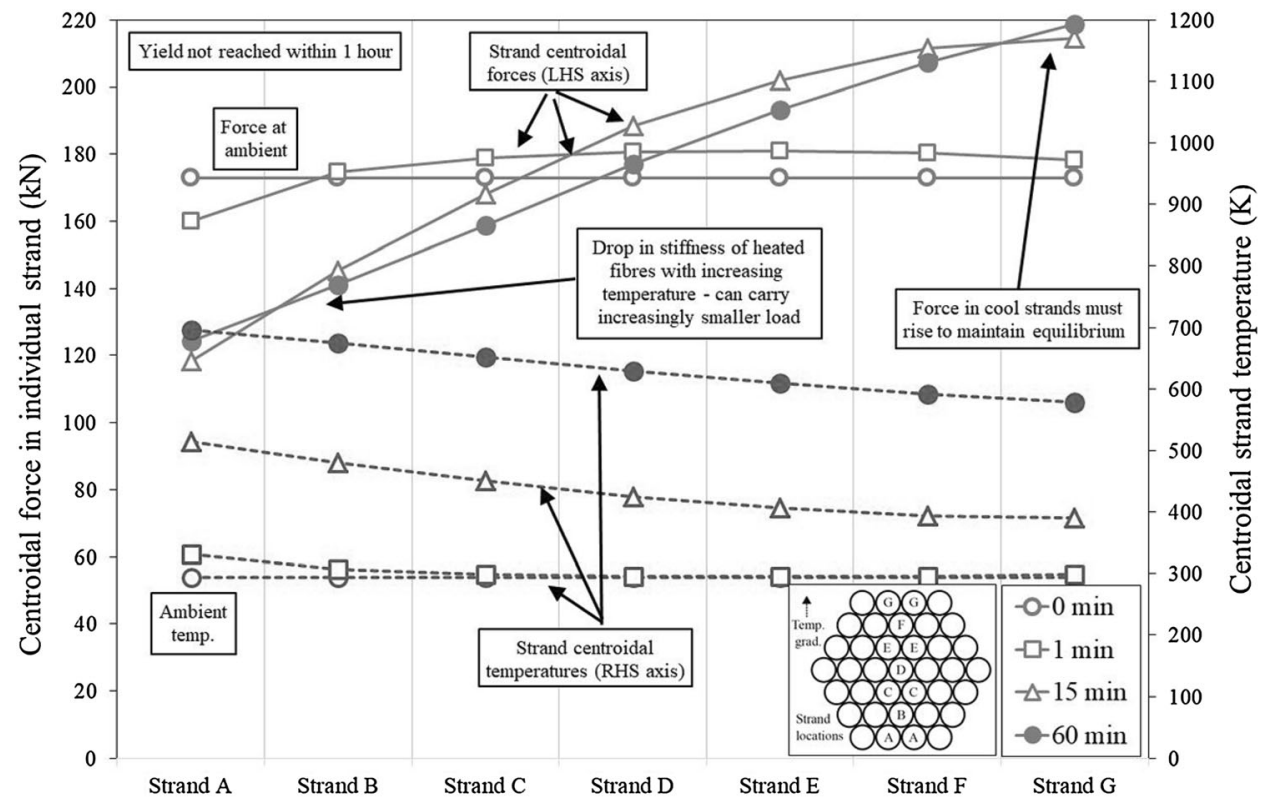

\section{Figure 11. Centroidal axial forces and temperatures in individual strands as a function of time in the unprotected heterogeneous configurations for fire scenario 2.}

\subsection{Fire Scenario 3}

The heating regime of fire scenario 3 induces a temperature gradient in two directions, and the predicted evolution of temperatures at three locations relative to the portion of the circumference in receipt of the radiative heat flux in each of the configurations is shown in Fig. 12. While none of the configurations or locations were found to attain the onset of damage temperature within 120 min of heating, the more realistic heterogeneous configuration again predicts significantly higher temperatures close to the heated perimeter than the uniform configuration. Further, the redistribution of centroidal strand forces (Fig. 13) by the unsymmetrical heating regime induces significant and approximately equal biaxial bending moments with a maximum magnitude of approximately $14 \%$ of the ambient yield moment (Fig. 9). This response would again be entirely missing from a simple lumped capacitance treatment (the error $e$ reaches approximately $8 \%$ in the initial stages of heating, again suggesting such a treatment could have been appropriate).

It should be added that all sets of moments shown in Fig. 9 were normalised by the first yield moment assuming ambient material properties for simplicity. However, as the first yield moment degrades with increasing temperature, this ratio will in fact tend towards unity with increasing heating duration for all fire scenarios investigated here, a particularly unfavourable response that is undetectable using only simplified thermal treatments. 


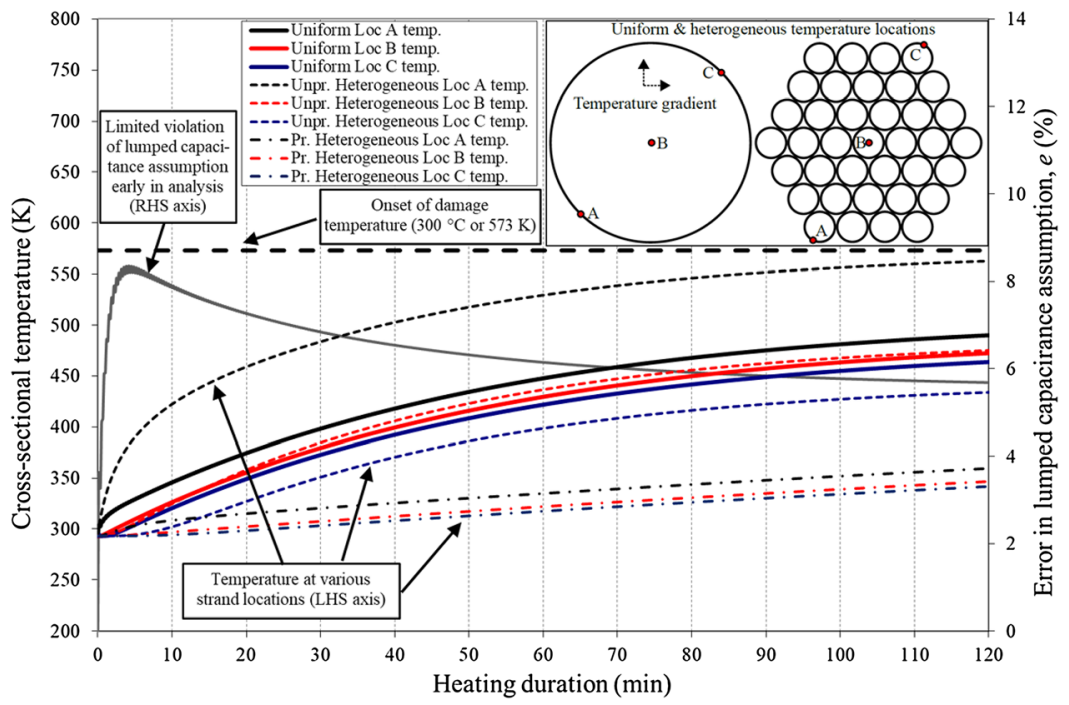

Figure 12. Temperature-time distributions at different locations in the uniform and heterogeneous configurations for fire scenario 3 and the error in lumped capacitance based on the heterogeneous configuration. "Pr."' denotes the heterogeneous configuration with 120 min blanket fire protection.

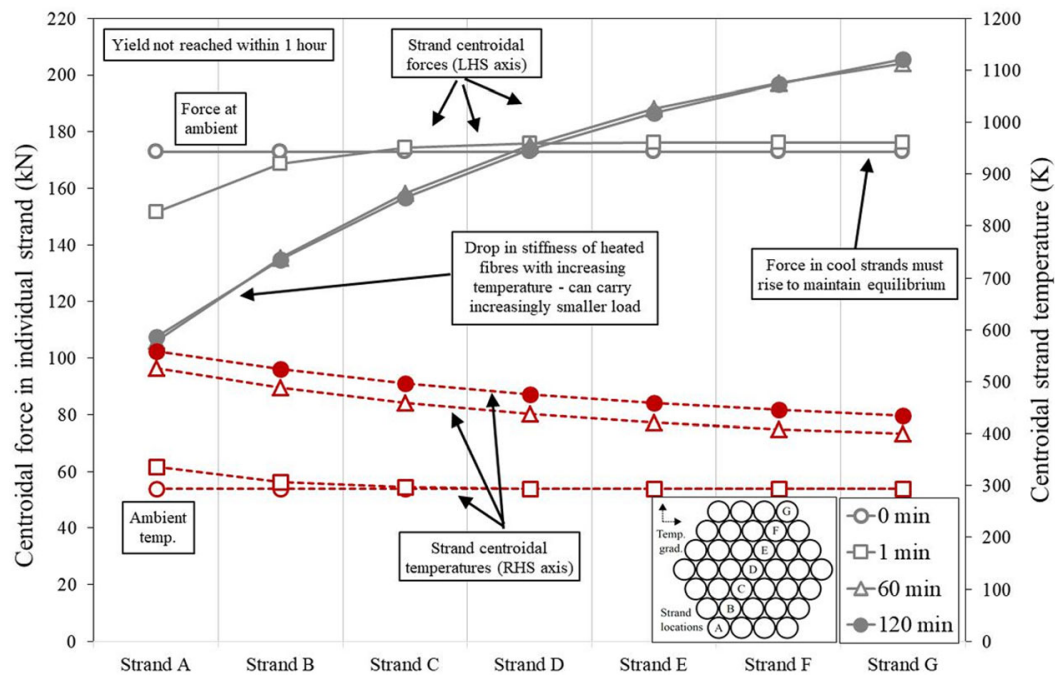

Figure 13. Centroidal axial forces and temperatures in individual strands as a function of time in the unprotected heterogeneous configurations for fire scenario 3. 


\section{Conclusions}

This paper has proposed a novel thermomechanical methodology for assessing the cross-sectional response of structural multi-strand cables under fire-related thermal loads. In establishing the state of the art in the literature of cables under fire, it was identified that previous research had not presented a detailed methodology based on fundamental principles. In the present treatment, heat transfer between individual strands is assumed to occur by conduction and radiation across the contact surface and interstitial air cavities respectively, with the air cavities typically being too narrow to permit convection. The methodology has been validated against two experiments of cables subject to radiant heating and an input sensitivity analysis was undertaken showing the contact resistance and the material conductivity to be the influential parameters. It is rare for a heat transfer methodology for cables to receive validation against experimental evidence due to the scarcity of experimental data available in the literature.

The thermomechanical performance was also considered at a two-dimensional level. This represents an advance on simplified treatments described elsewhere in the literature which often rely on uniform or lumped capacitance thermal models. The authors' model is presented as a general template containing the underlying physics to aid those performing such studies regardless of cable configuration. Future research should consider experiments on the thermomechanical performance of cables and the further calibration of input parameters of the proposed model, as well as an extension to a three-dimensional configuration.

The appropriateness of adopting the simplified models such as those which assume lumped capacitance over the more rigorous proposed methodology applicable to heterogeneous cross-sections was explored through three qualitatively different scenarios of fire exposure, one leading to severe uniform heating and two less severe but non-uniform exposures leading to uniaxial and biaxial temperature gradients respectively. The latter scenarios have not been studied in previous research. In all cases considered here, a heterogonous treatment with explicit modelling of strands was found to lead to a more accurate and conservative prediction of temperature evolution than a simpler uniform one, predicting an earlier onset of damage than that according to a simplified but widely-used temperature failure criterion. The discrepancy was found to be particularly significant, and a lumped capacitance assumption thus particularly unconservative from a thermomechanical perspective, under unsymmetrical heating regimes. Additionally, the authors' methodology qualitatively predicts the realistic 'load shedding' phenomenon known to occur in multi-strand cables that was rarely reproduced in previous numerical studies.

Additionally, it was shown that while the lumped capacitance assumption, often adopted in previous studies, can be taken as 'valid' on the basis of only temperature predictions from heat transfer analyses, such conclusions must be treated with great care as the analysis may not always be conservative in mechanical terms. In particular, unsymmetrical heating regimes may induce significant net bending moments on the cable cross-section leading to an unfavourable structural response that cannot be assessed on the basis of temperatures alone, even where 
the differences between the highest and lowest cross-sectional temperatures are deemed 'small'. This applies also to protected cables which, although they experience significantly reduced temperatures, similarly develop moments under non-uniform heating regimes. This finding and its potential consequences in terms of mechanical performance do not appear to have been extensively considered in previous studies. Further research should consider experiments of loaded cables and three dimensional models to examine whether such phenomena reproduced in two dimensional models need further investigation.

\section{Acknowledgements}

Arup is acknowledged for supporting the first author in carrying out this research.

\section{Open Access}

This article is distributed under the terms of the Creative Commons Attribution 4.0 International License (http://creativecommons.org/licenses/by/4.0/), which permits unrestricted use, distribution, and reproduction in any medium, provided you give appropriate credit to the original author(s) and the source, provide a link to the Creative Commons license, and indicate if changes were made.

\section{Appendix: Model Validation and Input Sensitivity Analysis}

\section{Introduction}

This appendix describes the validation of the proposed heat transfer methodology described in Sect. 3.1 of this paper through the assessment of the thermal response of unloaded cable specimens against a set of hitherto unpublished experiments. Unfortunately, only very limited experimental evidence exists on the mechanical response of cables due to the practical difficulties in testing loaded large diameter long-span cables until failure. The mechanical response model described in this study therefore will benefit from further calibration based on future experimental evidence as it becomes available. Such studies should additionally highlight the potential influence of the applied load on the thermal performance of the cables.

The thermomechanical model presented in this paper requires a significant number of inputs, as discussed in Sects. 3.1 and 3.3. A 'one-at-a-time' (OAT) input sensitivity analysis was therefore additionally undertaken based on the same model geometry as used for the validation study to assess the effect that variations in different input parameters may have on the stability of the model prediction. This study will help to inform which model input parameters should be prioritised in future research. 


\section{Experiments on Thermal Performance of Unloaded Cables}

Only very few experiments have ever been performed with the aim of understanding the thermal behaviour of steel cables. Those that have been performed considered only either uniform axisymmetric heating by placing a cable sample in an oven [26, 27] or asymmetric heating from one side [27, 28]. Degasperi [26] tested two cable assemblies: a Locked Coil rope and a Warrington Seale rope (6 spiral strands twisted around a polymeric core). The cables were uniformly heated in a custom-made oven of the size $1 \mathrm{~m} \times 0.62 \mathrm{~m} \times 1 \mathrm{~m}$ that can reach temperatures of $900^{\circ} \mathrm{C}$. The oven was designed to host a cable with a maximum diameter of $90 \mathrm{~mm}$ and to enclose a length of $500 \mathrm{~mm}$. The cable specimens were placed in the oven which followed a heating regime according to the ISO 834 standard temperature-time curve, while the temperature was measured at different cross-sectional locations through the cable specimens. According to the authors of these experiments, the set up was complex as the insertion of thermocouples into the tight cable assemblies was not straightforward. The specimens were thus disassembled, with some wires taken out to make space for the thermocouples. For the locked coil rope, a thermocouple was placed in each of the three internal rings as well as on the external surface to measure the temperature rise. For the Warrington Seale rope, temperatures were recorded at the surface and at one internal location, but no information was given on the exact position of the internal thermocouples. The experiments were repeated twice for each cable assembly. However, repeatability is not straightforward due to the difficulties in placing thermocouples inside cable assemblies.

A series of small-scale experiments have also been carried out at the University of Edinburgh [27, 28]. The temperatures in the samples were recorded via K-type thermocouples at different locations within the cable cross-section. Milne [28] tested existing cable specimens that were once part of a construction project and were provided by a manufacturer. Due to the difficulty in inserting thermocouples inside the samples, in the next set of experiments by Lugaresi [27] the specimens were assembled in the lab from straight steel rods which facilitated the insertion of thermocouples. The experiments at the University of Edinburgh were the first attempt to measure the temperature increase inside a cable assembly due to asymmetric heating. This heating regime was obtained by placing the cable specimens in front of a radiative propane panel. Before starting the test, the panel was ignited and was allowed to reach a steady state so as to emit a constant heat flux. For each experiment, the incident heat flux on the cable surface was measured with a heat flux gauge. Lugaresi [27] additionally considered experiments of specimens under uniform heating. The cable specimens were inserted in an oven and exposed to transient heating.

\section{Validation Against the Experiments by Lugaresi}

The experiments of Lugaresi [27] were chosen by the authors for the purposes of an initial validation study of the heat transfer methodology because there is less uncertainty in the location of the thermocouples and the repeatability of the results as the specimens were put together by the researchers rather than been 


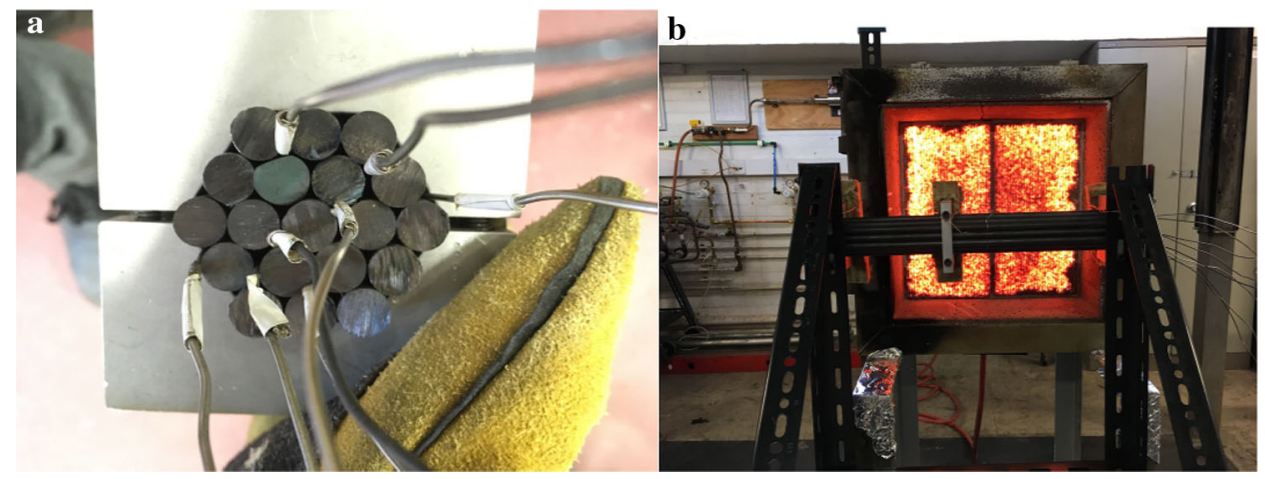

Figure 14. Experiments by Lugaresi [27]; (a) insertion of thermocouples; (b) radiant panel.

\begin{tabular}{llr}
$\begin{array}{l}\text { Table } 2 \\
\text { Dimensions of Each Cable Configuration Tested by Lugaresi [27] }\end{array}$ \\
\hline Cable specimen & A & B \\
\hline Wire diameter $(\mathrm{mm})$ & 10 & 10 \\
Long diagonal $(\mathrm{mm})$ & 50 & 70 \\
Short diagonal $(\mathrm{mm})$ & 44.6 & 62 \\
\hline
\end{tabular}

provided by a manufacturer. Additionally, the same specimens were exposed to both uniform and asymmetric heating and thus offer more opportunities for calibration of parameters (although it should be noted that the uniform exposure is not analysed in this paper). Two cable specimens consisting of a hexagonal arrangement of uniform cross-section steel bars were used in the experiments by Lugaresi [27], as shown in Fig. 14 with geometry summarised in Table 2. The experiments conducted with the asymmetric heating applied by a radiation panel from one side are used in this validation study as they lead to larger thermal gradients in the cable and therefore are more appropriate to test the assumptions of the current methodology.

To validate the model against the experimental data, the boundary conditions imposed during the experiments need to be accurately defined. An important parameter is the incident heat flux on the external surface of the cable since it has been identified as one of the variables the have a major effect on the model outcome. The cable was heated from one side by a radiating panel, and the incident radiative heat flux on the surface of the cable sample during testing was measured with a Schmidt-Boelter heat flux gauge. However, the incident flux calculated in this way is relative to a small surface parallel to the radiating surface, and this requires a correction because the constituent bars have concave surfaces. Radiation received by a surface depends on its orientation with respect to the radiation source and is thus a function of the angle of incidence. To account for this in the 


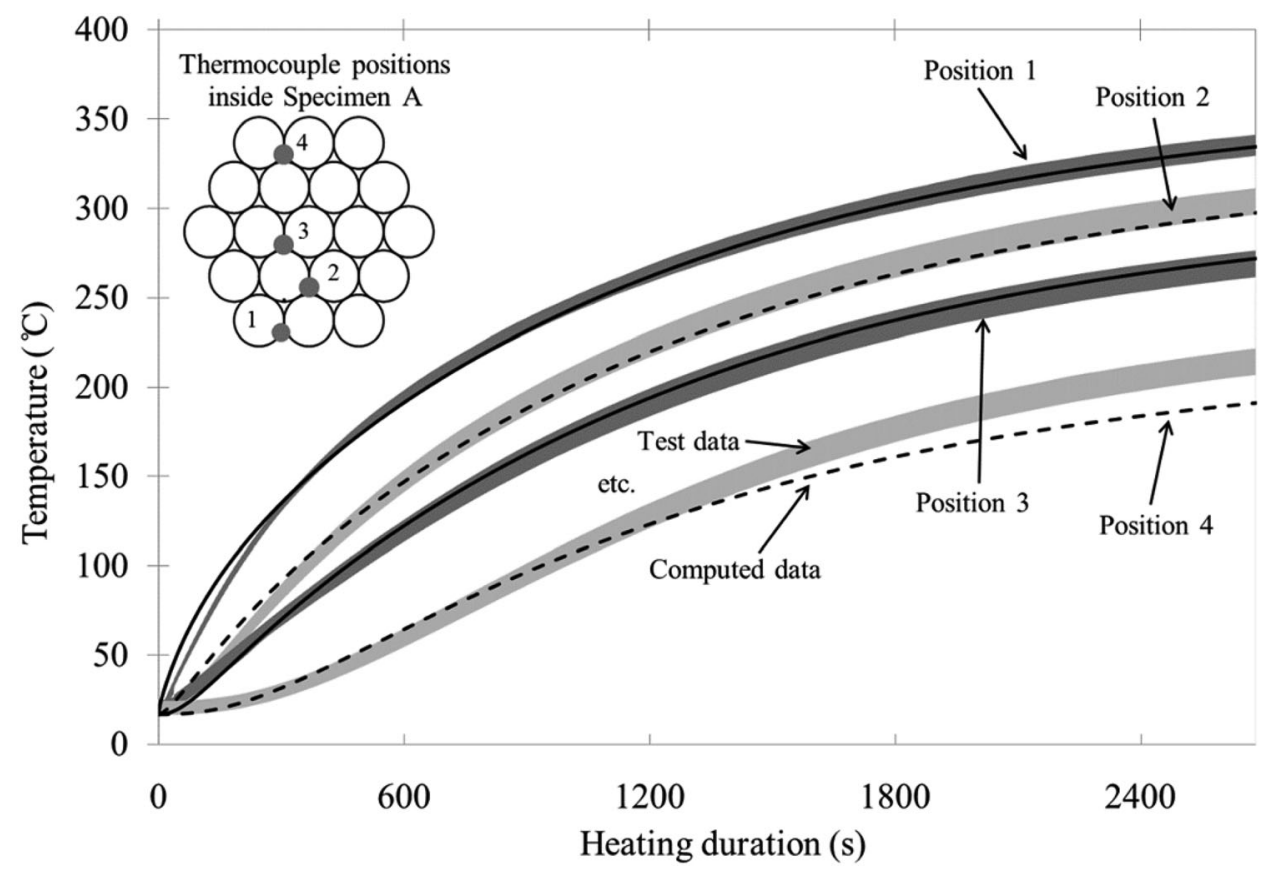

\section{Figure 15. Model predictions (solid and dashed lines) against the experimental measurements (shaded area) for the small diameter Specimen A of Lugaresi [27].}

model, the flux was defined for each bar as a $\cos (\theta)$ function corresponding to a cylindrical coordinate system with the origin on the centre of the strand. This results in a heat flux with a maximum value on the surface of the bar directly facing the panel $(\theta=0)$ and is equal to zero at a point on the surface located at $\theta= \pm 1 / 2 \pi$ on either side.

During experiments, it was observed that some of the bars in the specimen were not in contact. A visual inspection was performed to determine which bars were not in contact during testing and at the identified regions no contact conduction was allowed in the finite element model. The temperatures recorded by Lugaresi [27] were compared to the temperature predicted by the proposed heat transfer model in Sect. 3.1 as implemented in ABAQUS. The measured and predicted temperature-time histories are illustrated in Figs. 15 and 16 respectively for cable specimens A and B respectively (as defined in Table 2) at four different locations through their respective cross-sections. Note that the model results are shown as solid lines while the experimental results are shown as clouded areas to cover the range of the various tests performed. It can be seen that the finite element model, and thus the constituent heat transfer methodology, compares very well with the experimental results in capturing the trends of the thermal gradients. 


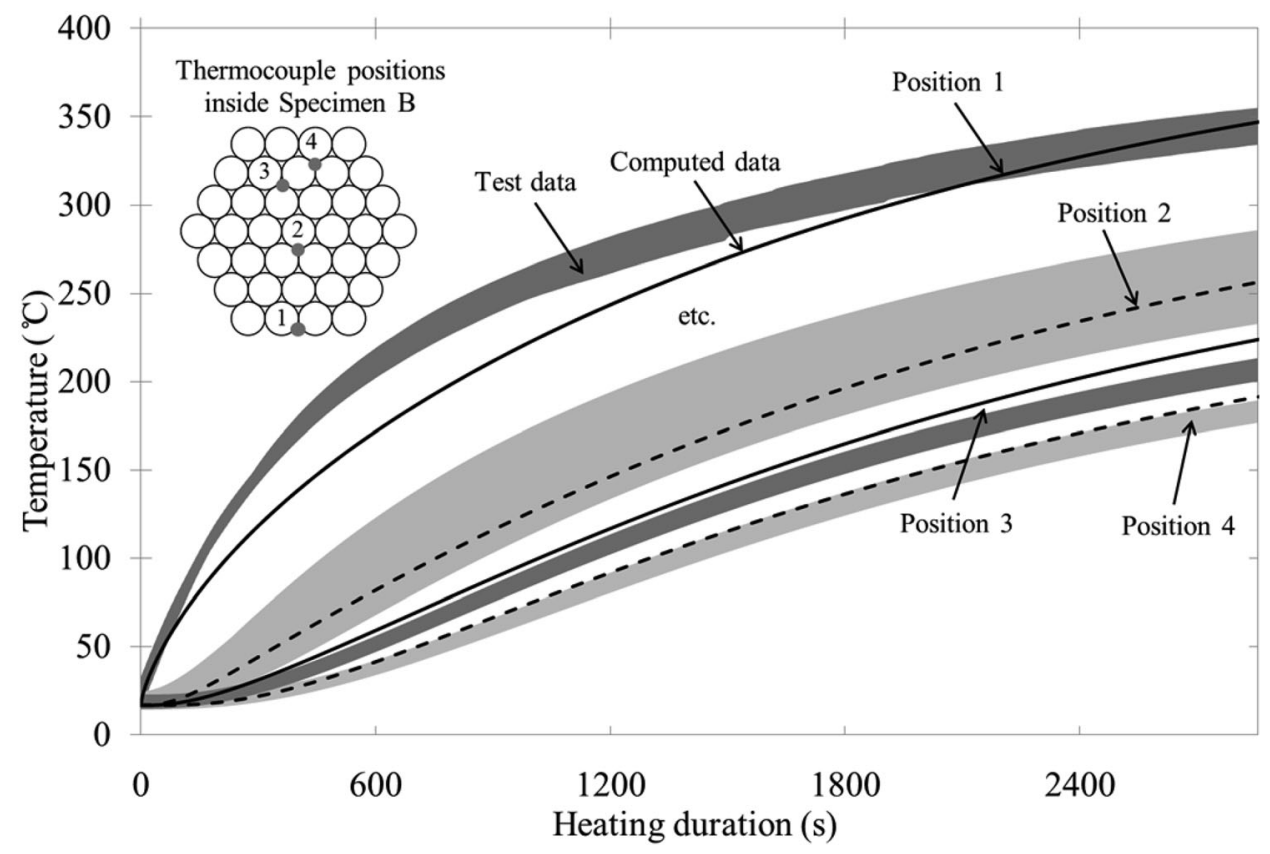

\section{Figure 16. Model predictions (solid and dashed lines) against the experimental measurements (shaded area) for the large diameter Specimen B of Lugaresi [27].}

\section{'One-at-a-Time' Input Sensitivity Analysis}

A base model needs to be defined to undertake a 'one-at-a-time' (OAT) sensitivity analysis on the basis of a best estimate for each input from the available literature. The inputs of the base model can be then changed individually to test their sensitivity on the stability of predictions of the system. The base model input parameters are summarized in Table 3. The nominal values were extracted from literature and selected to correspond to the heating regime of the Lugaresi [27] asymmetric heating tests (radiation impinging on half the cables surface). As part of the OAT sensitivity analysis, each individual parameter was increased by $25 \%$, then by $50 \%$ and then decreased by $25 \%$ and then by $50 \%$ while all others were kept constant. The subsequent prediction of the system was assessed according to an output metric (defined shortly) and compared to the prediction for the base model according to the same metric.

The contact width was included in heat transfer parameters since the conductive heat transfer across strands depends on its magnitude. If the contact width is increased, the contact resistance will decrease, resulting in a higher rate of heat transfer between strands. The contact width depends on the contact force, thus the variation in the force affects the outcome in the similar way: a greater force leads to a larger contact and thus a faster rate of heating. The cable samples were heated from one side with a radiating panel and therefore the heat transfer mech- 


\section{Table 3}

Base Model Inpuł Parameters [27]

\begin{tabular}{lll}
\hline Parameter & \multicolumn{1}{c}{ Nominal value } & \multicolumn{1}{c}{ Reference } \\
\hline Strand diameter & $0.01 \mathrm{~m}$ & Lugaresi [27] \\
Interaction surface & $5.24 \times 10^{-3} \mathrm{~m}^{2}$ & Atalioti [29] \\
Length & $1 \mathrm{~m}$ & Unit length assumption \\
Poisson ratio of steel & 0.3 & EN 1993-1-2 [22] \\
Elastic modulus of steel & $210 \mathrm{GPa}$ & EN 1993-1-2 [22] \\
Conductivity of steel & Temperature-dependent & Bentz and Prasad [30] \\
Heat capacity of steel & Temperature-dependent & Bentz and Prasad [30] \\
Density of steel & $7850 \mathrm{~kg} / \mathrm{m}^{3}$ & EN 1993-1-2 [22] \\
Emissivity of steel & 0.7 & EN 1993-1-2 [22] \\
Conductivity of air & $0.0263 \mathrm{~W} /(\mathrm{m} \mathrm{K})$ & Incropera et al. [19] \\
Convective heat transfer coefficient & $15 \mathrm{~W} /\left(\mathrm{m}^{2} \mathrm{~K}\right)$ & Incropera et al. [19] \\
Incident heat flux & $23.2 \mathrm{~kW} / \mathrm{m}^{2}$ & Lugaresi [27] \\
Ambient fluid temperature & $293 \mathrm{~K}$ & Lugaresi [27] \\
Ambient surface temperature & $293 \mathrm{~K}$ & Lugaresi [27] \\
Contact width & $8.1695 \times 10^{-7} \mathrm{~m}$ & McGee et al. [18] \\
Contact force (self-weight) & $6 \mathrm{~N}$ & n/a \\
\hline
\end{tabular}

anisms considered was radiation to the surface of the cable facing the heat source. The constant surface heat flux was measured during testing with the aid of a high precision temperature gauge. As the cable was not surrounded by flames or by smoke, cooling convection was included from the external surface of the cable to the environment $\left(T_{\operatorname{sink}}=293 \mathrm{~K}\right)$. Radiation to the surroundings was also modelled and the enclosing surface was assumed to be at ambient temperature $\left(T_{\text {sur }}=\right.$ $293 \mathrm{~K})$. The convective heat transfer coefficient was calculated following the Incropera et al. [19] procedure for cylinders in cross flow, treating the cable as a homogeneous cylinder with a hexagonal geometry.

To understand how sensitive the model is to each input parameter, the changes in the output function are used as a metric to quantify the effect of the parameter variability on the model predictions. Although the model has many possible outputs, an outcome function was selected that permits the estimation of a linear cross-sectional temperature gradient component. This temperature component was chosen as it structurally meaningful, in that it is linked to the differential thermal expansion of the cables and the possible stresses and bending moments that may arise in the cable due to heating [31]. From the finite element model output, it is possible to extrapolate the nodal temperatures at different locations along the cable's centreline (e.g. akin to path 1-2-3-4 in Fig. 16). The cross-sectional temperature distribution obtained in this way is nonlinear at each time step due to the transient nature of the heat flow, but a conservative approximation of the linear cross-sectional temperature gradient may be found by normalising the difference between opposing fibre temperatures by the section depth, or $\Delta T / d$. The maximum value of this approximate gradient over any simulation was then taken as the output metric.

The relative sensitivity of each input parameter is shown in Figs. 17 and 18, expressed as a percentage change in the output metric against the percentage 


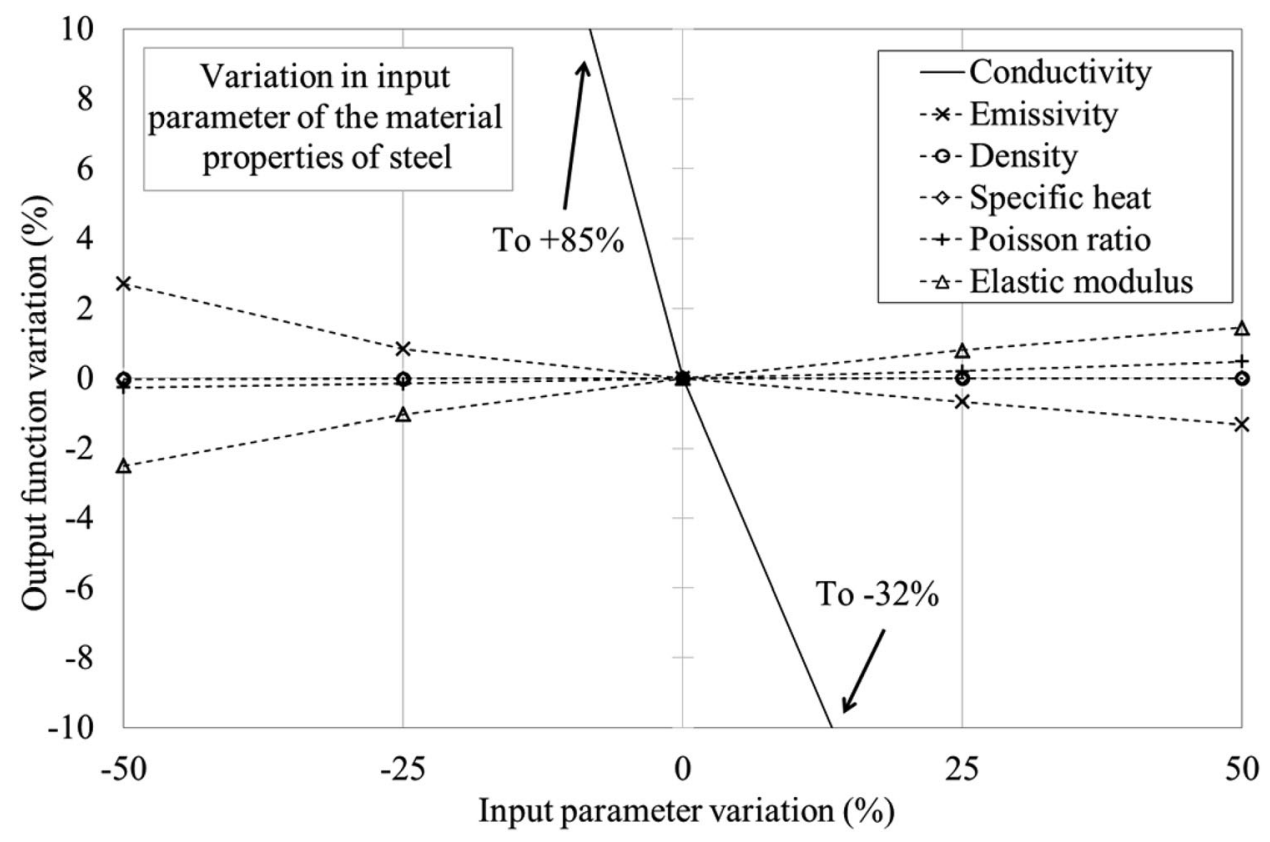

Figure 17. Sensitivity of model to variation in input material parameters for steel.

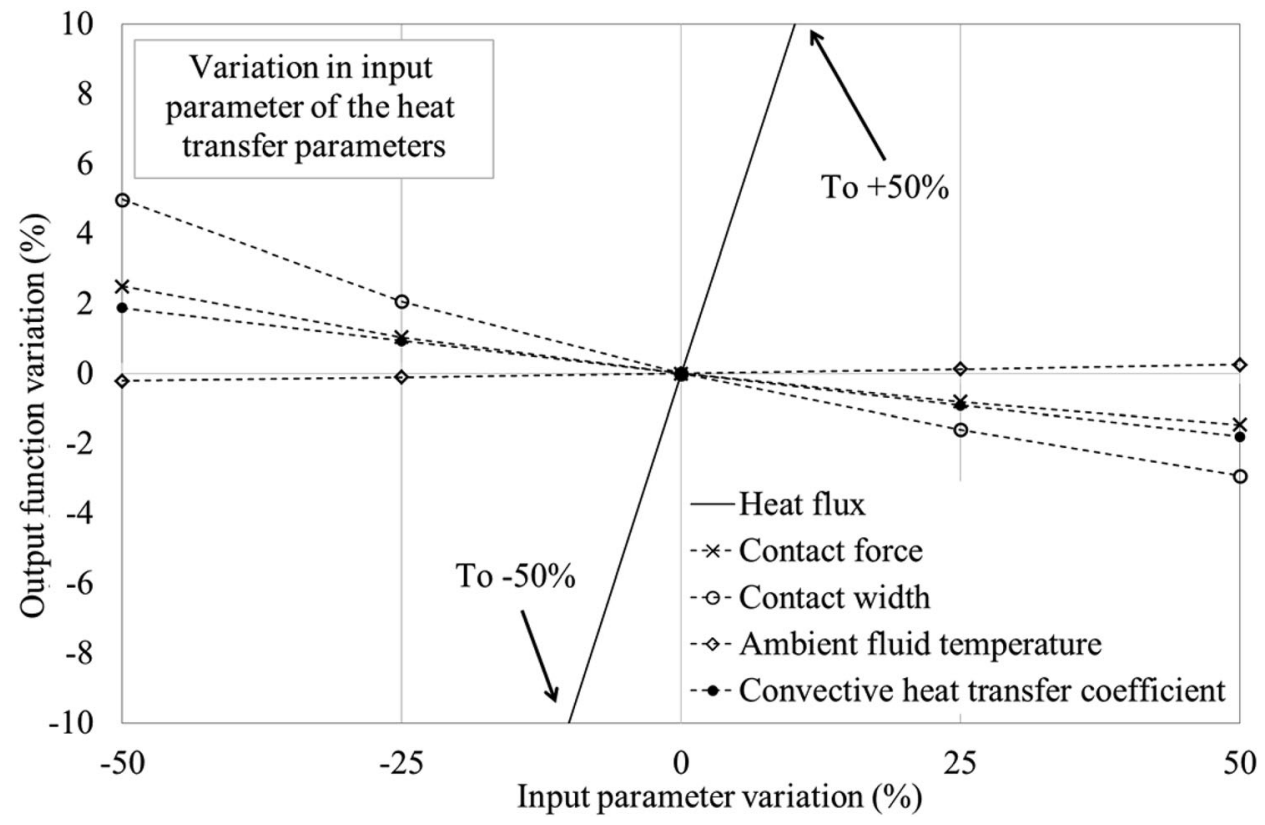

Figure 18. Sensitivity of model to variation in input heat transfer parameters. 
change in the given input parameter. The OAT sensitivity analysis demonstrates that the variation of the surface heat flux $q$ " produces by far the largest variation in the model output. This is because a high incident heat flux causes high internal temperature gradients, and although the temperature of the heated side rises rapidly its transient conduction into the remainder of the cross-section occurs relatively slowly. A lower heat flux, on the other hand, heats the cable slowly and the rate of absorption is comparable to the rate of internal heat conduction, resulting in a more uniform temperature distribution. For the same reason, the thermal conductivity of the steel was found to be the governing material parameter as it controls heat flow through the solid strands and across the contact width. Changes of all other heat transfer and material parameters had only a very minor influence on the output function (up to less than $5 \%$ change of output for a $50 \%$ change of input).

\section{References}

1. Garlock M, Paya-Zaforteza I, Kodur V, Gu L (2012) Fire hazard in bridges: review, assessment and repair strategies. Eng Struct 35:89-98

2. Peris-Sayol G, Payá-Zaforteza I, Balasch-Parisi S, Alós-Moya J (2016) Detailed analysis of the causes of bridge fires and their associated damage levels. ASCE J Perform Constr Facil 31(3):04016180

3. PTI DC45.1-12 (2012) Recommendations for stay-cable design, testing, and installation. Post-Tensioning Institute, Farmington Hills

4. Kotsovinos P, Flint G, Walker G, Lane B (2016a) Qualitative assessment of the fire hazard beneath bridges. In: Proceedings of 14th international conference and exhibition on fire science and engineering INTERFLAM, Royal Holloway College, UK, 4-6 July

5. Kotsovinos P, Walker G, Flint G, Lane B (2016b) Assessing the fires on the deck of cable stayed bridges. In: Proceedings of 9th international conference on structures in fire, Princeton, USA, 8-10 June

6. Alos-Moya J, Paya-Zaforteza I, Garlock MEM, Loma-Ossorio E, Schiffner D, Hospitaler A (2014) Analysis of a bridge failure due to fire using computational fluid dynamics and finite element models. Eng Struct 68:96-110

7. Aziz EM, Kodur VK, Glassman JD, Garlock MEM (2015) Behavior of steel bridge girders under fire conditions. J Constr Steel Res 106:11-22

8. Quiel SE, Yokoyama T, Mueller K, Bregman L, Marjanishvili S (2015) Mitigating the effects of a tanker truck fire on a cable-stayed bridge. In: Proceedings of 2nd international conference on performance-based and lifecycle structural engineering, Queensland, Australia, 9-11 September

9. Fontanari V, Benedetti M, Monelli BD, Degasperi F (2015) Fire behaviour of steel wire ropes: experimental investigation and numerical analysis. Eng Struct 84:340-349

10. Bennetts I, Moinuddin K (2009) Evaluation of the impact of potential fire scenarios on structural elements of a cable-stayed bridge. J Fire Prot Eng 19(2):85-106

11. Main JA, Luecke WE (2010) Safety assessment of parallel wire suspension bridge cables under thermal effects. NIST Technical Note, Report No. 1678

12. Quiel SE, Yokoyama T, Bregman LS, Mueller KA, Marjanishvili SM (2015) A streamlined framework for calculating the response of steel-supported bridges to open-air tanker truck fires. Fire Saf J 73:63-65 
13. Woodworth M, Hansen E, McArthur C, Abboud N (2015) Protection of cable-stay bridges from accidental and man-made fire hazards: a rational physics-based approach to analysing vulnerabilities and mitigations. In: Proceedings of ASCE structures congress 2015, Portland, Oregon, April 23-25, pp 24-37

14. FATZER (2017) Seilbau - structural ropes. Commercial product catalogue, FATZER AG Seilbau, Romanshorn, Switzerland

15. REDAELLI (2017) Redaelli Flexpack steep wire rope. Commercial product brochure, REDAELLI Milan, Italy. http://www.redaelli.com/en/products/ropes/flexpack/. Downloaded 12 Oct 2017

16. INEOS (2017) Typical engineering properties of high density polyethylene. Fact sheet, INEOS Olefins \& Polymers USA. https://www.ineos.com/globalassets/ineos-group/busi nesses/ineos-olefins-and-polymers-usa/products/technical-information-patents/ineos-typi cal-engineering-properties-of-hdpe.pdf. Downloaded 12 Oct 2017

17. Yovanovich MM, Coutanceau J (1969) Sur la détermination de la résistance thermique transversale d'un cylindre de révolution homogène isotrope avec des conditions aux limites mixtes. CR Acad Sci Paris 268:B821-B823

18. McGee GR, Schankula MH, Yovanovich MM (1985) Thermal resistance of cylinderflat contacts: theoretical analysis and experimental verification of a line-contact model. Nucl Eng Des 86(3):369-381

19. Incropera FP, Dewitt DP, Bergman TL, Lavine AS (2013) Foundations of heat transfer, 6th edn. Wiley, London

20. ABAQUS (2016) ABAQUS v. 2016. Commercial FE Software and Documentation, Dassault Systèmes, Simulia Corporation, Providence, RI, USA

21. Usmani AS, Rotter JM, Lamont S, Sanad AM, Gillie M (2001) Fundamental principles of structural behaviour under thermal effects. Fire Saf J 36:721-744

22. EN 1993-1-2 (2005) Eurocode 3: design of steel structures-Part 1-2: general rules - structural fire design. Comité Européen de Normalisation, Brussels

23. PESTEC (2017) FPB 1200 fire protection blanket. Commercial product brochure, PESTEC, Bad Sodenm Germany. http://www.pes-tec.com/images/pestec-docs/products/PR199-FPB-1200/DS-199-FPB-1200-Fire-Protection-Blanket.pdf. Downloaded 14 Oct 2017

24. Lowesmith BJ, Hankinson G, Acton MR, Chamberlain G (2007) An overview of the nature of hydrocarbon jet fire hazards in the oil and gas industry and a simplified approach to assessing the hazards. Process Saf Environ Prot 85(3):207-220

25. Drysdale D (2011) An introduction to fire dynamics, 3rd edn. Wiley, London

26. Degasperi F (2009) Modalita' e problematiche di prova per la verifica di resistenza al fuoco delle funi in acciaio. Associazione Italiana di Metallurgia, Trenta

27. Lugaresi $F$ (2017) Thermal response of structural spiral strands subject to fire. BEng Thesis, The University of Edinburgh, UK

28. Milne CAW (2016) Fire performance of spiral strand steel cables. MEng Thesis, The University of Edinburgh, UK

29. Atalioti A (2016) Thermal response of structural cables subjected to fire. MSc Dissertation, Imperial College London, UK

30. Bentz DP, Prasad KR (2007) Thermal performance of fire resistive materials. I: characterization with respect to thermal performance models. NISTIR 7401, National Institute of Standards and Technology, USA

31. Ghali A, Neville A, Brown TG (2009) Structural analysis: a unified classical and matrix approach, 6th edn. CRC Press, Boca Raton

Publisher's Note Springer Nature remains neutral with regard to jurisdictional claims in published maps and institutional affiliations. 